Research Article

\title{
Differential Game and Simulation Study on Management Synergy of Regional Coal Mine Emergencies in China
}

\author{
Yu Hao, ${ }^{1}$ Chaolun Sun $\mathbb{D}^{2,3}$ Jianping Wei, ${ }^{2,3}$ Sasa Gu, ${ }^{4}$ and Fan Zhang $^{1}$ \\ ${ }^{1}$ Safety and Emergency Management Research Center, Henan Polytechnic University, Jiaozuo 454000, China \\ ${ }^{2}$ College of Safety and Engineering, Henan Polytechnic University, Jiaozuo 454000, China \\ ${ }^{3}$ State Key Laboratory Cultivation Base for Gas Geology and Gas Control, Henan Polytechnic University, Jiaozuo 45400, China \\ ${ }^{4}$ School of Marxism Studies, Henan Polytechnic University, Jiaozuo 454000, China \\ Correspondence should be addressed to Chaolun Sun; suncl@hpu.edu.cn
}

Received 8 September 2021; Accepted 6 November 2021; Published 30 November 2021

Academic Editor: Gan Feng

Copyright $\odot 2021 \mathrm{Yu}$ Hao et al. This is an open access article distributed under the Creative Commons Attribution License, which permits unrestricted use, distribution, and reproduction in any medium, provided the original work is properly cited.

\begin{abstract}
Emergency management of coal mines requires enhanced synergy among departments, institutions, and enterprises, which means overall efficiency in management. Their synergy can effectively lower the cost of emergency management, improve the effectiveness of it, and build a strong joint force for the prevention and control of emergencies. Accordingly, this study established a synergy system for regional coal mine emergency management and analyzed the interest relationship among key stakeholders in the system. Then, it established differential game models of the management synergy, explored the selection process of the behavior strategy of each stakeholder under different situations, and provided important tools for quantitative analysis on emergency management synergy practice. Furthermore, numerical simulation was carried out to analyze the influencing factors of their decision behaviors. The research results are of great significance for the comprehension of the evolution mechanism for the emergency management synergy of coal mines, the assistance for the government in determining the optimal method in emergency management synergy, the mobilization of the stakeholders, and the improvement of the current situation of emergency management synergy of coal mines in China.
\end{abstract}

\section{Introduction}

With the rapid development of coal mine industry and the promoted awareness of emergency management, improvement has been made in mining safety and emergency management of coal mines in China. However, with the continuous aging of coal mines and the increase in the mining depth, risk factors abound in mining safety. In addition, carelessness may result in major disasters because the coal mine disasters and accidents are of complexity, long term, suddenness, and repeatability. When a coal mine emergency (CME) occurs, the comprehensive improvement of CME prevention and control capacity requires a regional CME synergy mechanism to effectively coordinate the strengths of the government, relevant enterprises, and nongovernment entities. Therefore, whether from the perspective of national-level design or from the actual operation situation of coal mine enterprises, researches on CME management synergy deserve more attention, which is of far-reaching significance for the establishment of a longterm mechanism for safe mining in China.

Multiple subjects, including the central government, the local government, and coal mine enterprises, are involved in the regional CME management synergy system. The CME control requires coordination and cooperation of these stakeholders to improve the overall system function and to strengthen emergency management, hence minimizing CME-induced losses. Moreover, complicated interest conflicts remain due to different roles, interests, and preferences of these stakeholders in CME management synergy. Therefore, the regional CME management synergy is a complex game between different stakeholders. Based on this, this study introduced the differential game theory and established differential game models between the key 
stakeholders in the regional CME management synergy system. Then, it compared the influence of variables on the behavior of stakeholders and described the behavior of different subjects in the emergency synergy game. The research results provide important tools for quantitative analysis on CME management synergy practice. In addition, measures to mobilize stakeholders and improve the efficiency of CME management synergy are summarized, so as to find the optimal method to improve the CME management synergy, promote the establishment of regional CME management synergy mechanism, and contribute to the improvement of the capacity for regional CME management synergy.

\section{Current Situation of Emergency Management Synergy}

The word "synergy" comes from ancient Greek, and it is also called "coordination or cooperation" in practice. Generally, it refers to the ability or process of different individuals or resources to work together for the same goal. The idea of synergy has a long history, but synergetics was founded in 1971 as a systematic system by the famous physicist Hake. The main research content is the interaction between synergistic systems and subsets driven by extrinsic parameters. According to the theory of synergy which comes from the synergetics, in the process of public management, government, nongovernmental organizations, enterprises, and the masses play their respective roles in managing public activities to ensure the orderliness of public activities in the country [1]. Recent years have seen the wide application of the theory in the field of public management. "Synergistic effects" and "self-organization principles" have been widely applied to researches and practice of public management. However, there is a lack of unified definition for emergency management synergy in the academic world. Based on the connotation of synergy and previous research results, the concept of emergency management synergy herein is defined as follows: In order to prevent, control, and reduce accident losses, under the unified leadership of the government and relevant departments, the relevant subjects make rapid response in accordance with the synergy mechanism, make decisions scientifically, and fully share and optimize various resources in the emergency management to deal with the accidents or process of emergencies.

Emergency synergy is an emergency synergy relationship formed by multiple subjects through resource sharing and information exchange to achieve common emergency goals $[2,3]$. Emergency synergy extends the scope of emergency response organizations from government organizations to all relevant subjects besides government that may become emergency synergy partners [4]. From a practical point of view, strengthening construction of the emergency management synergy system is a common trend in the world to deal with emergencies at present, and it has also become a common phenomenon to form a differentiated collaborative network among emergency management functional agencies in the presence of an emergency disaster event [5]. In terms of theoretical research, researches on the emergency management theory in the international academic community not only emphasize prevention and preparation, but also focus on strengthening emergency management synergy. In recent years, studies on emergency management synergy by relevant scholars mainly shed lights on its functions, influencing factors, cases, etc. In terms of the function, scholars studied the response mechanism of emergency management synergy from the perspective of the subject and pointed out the importance of achieving effective emergency management synergy in the emergency management subjects. For example, McMaster et al., Salama et al., and Curnin et al. explored the importance of multidepartment cooperation in emergency response [6-8]. Hernandez and Serrano proposed the adoption of optimized collaborative knowledge management model to select much original information during emergency management, so as to improve emergency management [9]. In the aspect of the influencing factors of emergency management synergy, scholars have studied the influences of information, organizational structure, emergency resources, etc. For example, Guido held that an efficient allocation and interconnectivity of emergency resources were the key factors for emergency teams to achieve synergy [10]. Henstra considered that adequate emergency funds could meet the needs and expectations of the public and ensure the development of emergency collaboration among local governments [11]. Scholars began to conduct case studies on emergency management synergy after the September 11 attacks in the United States. For instance, Kapucu and Garayev analyzed tornado emergencies in Fort Worth, Texas, the United States, and believed that the amount of emergency information (lack or excess), lack of emergency equipment, lack of communication among new personnel for emergency management, conflicts of organizational authority, and language obstacles would affect the efficiency of emergency management synergy; furthermore, he believed that organizational cooperation was the fundamental guarantee for regional emergencies management [12]. According to the analysis on Hurricane Katrina in the United States, Calixto and Larouvere pointed out the factors influencing the efficiency of emergency management synergy: the differences in emergency norms and standards, the differences in the emergency phase of public emergencies, and the relations between organizations before emergencies [13]. There are few foreign researches on CME management synergy in the international community, because other countries correspond to a lower accident rate than China for their objective advantages including mechanization level and coal seam conditions. Chen et al. believed that it was both important and necessary to detect coal mine accidents in a timely manner and to handle the alarms accordingly. He proposed a wireless sensor network based on a real-time alarm processing method for coal mine safety [14]. Li et al. pointed out that after the occurrence of a coal mine accident, the key for preventing secondary accidents and reducing mortality was timely rescue. Therefore, they used simulation software to simulate the emergency management process based on the analysis of emergency rescue characteristics [15]. Qi and Ning addressed the problems of emergency management 
capacity in coal mines. Besides, under the guidance of synergistic thinking, they elaborated the concept and connotation of emergency management capacity in coal mines, constructed an evaluation model of emergency management capacity in coal mines, and conducted an empirical study [16].

Researches on CME management have become a hot issue for the government and academia in China in recent years. Compared with other countries, the Chinese academic researches on CME management began a little late yet embraced rapid development and fruitful results. According to the China national knowledge infrastructure database, the research on CME management started in 2002, grew rapidly in 2003, and reached its peak in 2020. An analysis on these documents found that the Chinese academic researches on CME management are mainly focused on emergency plans, management system, management capability, emergency rescue, and problems and solutions for emergency management [17-19]. Among them, research results of emergency plans correspond to the largest number. Many scholars have explored other topics, such as how to draw up emergency plans for coal mine enterprises, how to solve the problems in the emergency plans, and how to design emergency plan system for coal mines. For example, Zhen et al. put forward the system framework and preparation principles of the enterprise emergency rescue plans [20]. Zhang et al. studied the problems in the preparation of emergency plans for coal mine accidents in China and made relevant suggestions [21]. CME management synergy requires in-depth and systematic researches. However, at present, only a few researches are about emergency management and other research results, and they are mainly focused on decision-making, interflow of goods, influencing factors, evaluation, etc. [22]. For example, $\mathrm{Hu}$ et al. studied the significance of synergy between state-owned and local coal mines and held that it was necessary to sign a collaboration agreement [23]. Liu et al. elaborated the necessity of the establishment of disaster emergency rescue system between different regions of coal mines [24]. Yang et al. analyzed the current situation of the coal mine disaster rescue and verified the effectiveness of the CME rescue teams in terms of the CME rescue [25]. Several scholars explored the mechanism and capacity of coal mine safety emergency management synergy in China [26-29]. Wang et al. analyzed the evolutionary game between subjects in CME management synergy based on the evolutionary game theory and the numerical simulation method [30].

An analysis on the current situation of emergency management synergy in China and international community reveals that China just started to explore the emergency management synergy mechanism and yielded relatively few results, especially those about coal mines. Moreover, the emergency management synergy mechanism deserves more researches, and few researches were conducted on the game analysis on the dynamic behavior evolution of each subject in the system. Therefore, this study introduces the game theory to the CME management synergy mechanism to explore the evolutionary game behavior and synergy relationship among the CME management subjects and is aimed at guiding the establishment of the regional CME system and improving the emergency management synergy ability of these subjects.

\section{Model Establishment}

3.1. Analysis on the Interest Relationship in the Regional CME Management Synergy System. The key to emergency management synergy lies in how to maximize the benefits of collective action with existing rules while ensuring the rationality of the distribution of interests among the participating subjects. Emergency management synergy of coal mine disasters and accidents belongs to a kind of collective action involving multiple stakeholders. All the subjects involved have their own interest goals while achieving the shared organizational goals. The collective interests, also known as the regional public security, can be shared by all, but the benefit or loss of each participant may hinder the motivation of its investment due to the uncertainty of cost and benefit. As a result, tension and imbalance of the interests may occur among the participants, so balanced interests are the logical starting point and the core of CME management synergy. The process of regional CME management synergy is actually a game process that is carried out under the premise of interest relationship and conflicts. The interest relationship between key subjects in regional CME management synergy is shown in Figure 1.

\subsection{Analysis on the Game Relationship among Key Subjects in} the Regional CME Management Synergy System. In the process of CME management, there are indeed differences in the demands for benefits among the central government, the local government, and coal mine enterprises (including enterprises relevant to coal mines). The game process of the three subjects in pursuing the maximum of their own interests is the essence of the emergency management synergy process. When one subject is playing games with other subjects, it will adopt corresponding emergency strategies based on the pursuit of its own interests and the emergency management action of other subjects. The characteristics of coal mine emergencies require a high degree of cooperation among the central government, the local government, and coal mine enterprises. According to the needs of research, this study further simplifies the model, and only the emergency synergetic costs of the main coal mine enterprises and the local government are taken into consideration for establishing the differential game model (Figure 2).

3.3. Establishment of Differential Game Models for the Regional CME Management Synergy System. After an accident occurs, the local government and coal mine enterprises are the practitioners for CME management, and both parties need to pay for their corresponding emergency costs. Meanwhile, the emergency management work of coal mine enterprises shall be supervised and evaluated by the local government and shall receive corresponding rewards or punishments according to the evaluation results. The emergency management work of the local government is 




FIGURE 1: Interest relationship among main subjects in the regional CME management synergy system.

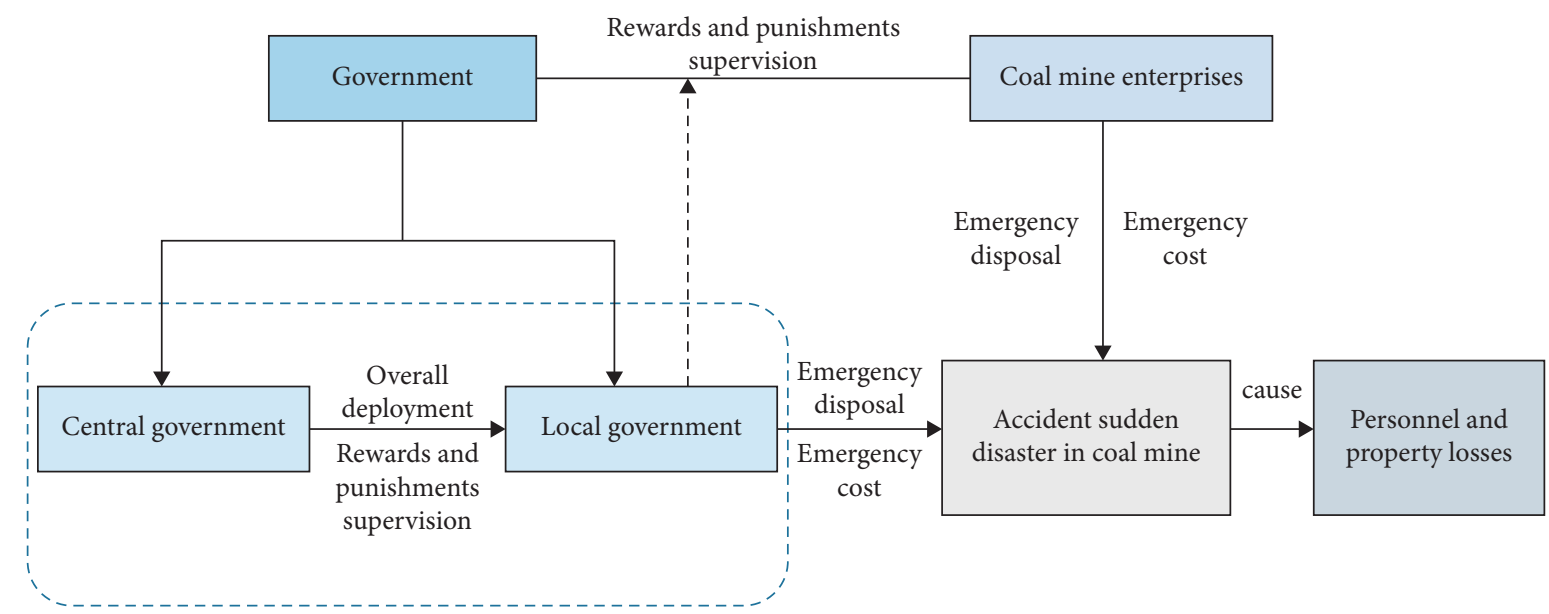

Figure 2: Game relationship among the central government, the local government, and coal mining enterprises.

instructed and arranged by the central government, also subject to its supervision and evaluation. The local government shall receive rewards or punishments according to the evaluation results. Based on the game relationship among coal mine enterprises, the central government, and the local government, this study makes the following assumptions on the model.

(1) The CME response involves coal mine enterprises, the central government, and the local government. As the information is not equally obtained, the three CME response subjects with limited rationality share a strategic relationship that can affect each other.

(2) When a CME occurs, the coal mine enterprises, the central government, and the local government will pay for the corresponding emergency costs for their participation in emergency work and will also acquire material or nonmaterial synergy benefits.
(3) The central government supervises the emergency management work of the local government and punishes or rewards it according to the results of its emergency work. The punishments mainly include administrative punishments such as removal of local government leaders from their posts.

(4) The local government supervises the emergency work of coal mine enterprises and punishes or rewards them based on the results and efforts paid in CME management. The punishments are mainly economic and administrative penalties such as removing the people in charge of the coal mine enterprises from their posts.

The state function $x^{*}(t)$ represents the state of coal mines in a sudden disaster. Specifically, it refers to the process from the occurrence of a $\operatorname{CME}(t=0)$ to the well control of it and consists of the personnel and property 
losses caused by CME as well as the reduced losses due to the efforts of relevant stakeholders. The formula is as follows:

$$
x^{*}(t)=x(t)+k x(t)-\gamma \varphi(t)-\gamma v(t),
$$

where $x\left(t_{0}\right)=x_{0} ; x^{*}(t)$ is the loss degree of a CME at the time of $t ; x(t)$ represents its dynamic change over time; $k x(t)$ is the diffusion effect of a CME. $k$ is the diffusion coefficient, which represents the change of the loss caused by the evolution and development of the CME. When $k>0$, the CME is deteriorating; when $k<0$, the CME is under control and the deteriorating situation is alleviated; $\varphi(t)$ and $v(t)$ represent the emergency efforts of the local government and coal mine enterprises, respectively; $\gamma \varphi(t)$ and $\gamma \nu(t)$ are the amounts of reduced loss by the emergency response efforts of the local government and coal mine enterprises, respectively; $\gamma$ represents the amount of reduced loss per unit effort; and $x_{0}$ represents the amount of the initial loss caused by the sudden accident.

$C_{1}[\varphi(t)]^{2} / 2$ is the emergency cost of the emergency response efforts $\varphi(t)$ by the local government for CME, where $C_{1}$ means the cost coefficient of the local government in CME. When $C_{1}>0$, the emergency cost of coal mine enterprises for CME is $\mathrm{C}_{2}[v(t)]^{2} / 2$, where $C_{2}$ represents the emergency cost coefficient for coal mine enterprises in CME. When $C_{2}>0$, the more the emergency efforts of each emergency subject pays, the higher the emergency cost for CME is.

Through the emergency management synergy, the synergetic benefits obtained by the local government and functional departments and coal mine enterprises are, respectively, $\alpha \gamma \varphi(t)$ and $\beta \gamma v(t)$, where $\alpha$ and $\beta$ represent the benefits brought to the local government and enterprises per unit reduced accident loss.

Rewards or punishments from the central government to the local government are displayed by $\eta \varepsilon_{\tau}\left[g_{\tau} \varphi(t)-g_{\tau 0} \varphi_{0}(t)\right] / 2$ where $\eta$ is the degree of rewards or punishments; $\varepsilon_{\tau}$ represents the degree of emergency supervision by the central government; $g_{\tau 0} \varphi_{0}(t)$ is an emergency performance evaluation standard set by the central government for the local government. $g_{\tau}$ is the emergency performance level coefficient. When $g_{\tau} \varphi(t)$ is larger than the critical value $g_{\tau 0} \varphi_{0}(t)$, the central government will reward the local government; otherwise it will punish the local government. The rewards or punishments from the local governments to coal mine enterprises are represented by $\mu \varepsilon_{c}\left[g_{c} v(t)-g_{c 0} v_{0}(t)\right] / 2$ where $\mu$ is the degree of rewards or punishments; $\varepsilon_{c}$ represents the degree of emergency supervision by the local government. $g_{c 0} v_{0}(t)$ is an emergency performance evaluation standard set by the local government for the coal mine enterprises, where $g_{c}$ is the emergency performance level coefficient. When $g_{c} v(t)$ is larger than the critical value $g_{c 0} v_{0}(t)$, the enterprises will be rewarded by the local government; otherwise they will be punished.

CME will result in certain losses or costs to the local government and coal mine enterprises, represented by $\theta x(t)$ and $\pi x(t)$, respectively. Table 1 lists the parameters of differential game models of the central government, the local government, and coal mine enterprises.

\section{Model Analysis}

4.1. Situation 1: No Rewards and Punishments Mechanism Is Introduced. The specific expression for the state of the CME is

$$
\begin{aligned}
& x^{*}(t)=x(t)+k x(t)-\gamma \varphi(t)-\gamma v(t), \\
& x\left(t_{0}\right)=x_{0} .
\end{aligned}
$$

The objective function of the emergency response by the local government is

$$
\int_{0}^{t}\left\{\alpha \gamma \varphi(t)-\frac{C_{1}}{2}\left[\varphi(t)^{2}\right]-\theta x(t)\right\}(t)^{-t} \mathrm{~d} t .
$$

The objective function of the emergency response by coal mine enterprises is

$$
\int_{0}^{t}\left\{\beta \gamma v(t)-\frac{C_{2}}{2}\left[v(t)^{2}\right]-\pi x(t)\right\}(e)^{-t} \mathrm{~d} t .
$$

If the local government and coal mine enterprises take emergency actions to maximize their interests, their objective functions are, respectively, as follows:

$$
\begin{aligned}
\max _{\varphi(t) \geq 0} \int_{0}^{t}\left\{\alpha \gamma \varphi(t)-\frac{C_{1}}{2}\left[\varphi(t)^{2}\right]-\theta x(t)\right\}(t)^{-t} \mathrm{~d} t, \\
\max _{v(t) \geq 0} \int_{0}^{t}\left\{\beta \gamma v(t)-\frac{C_{2}}{2}\left[v(t)^{2}\right]-\pi x(t)\right\}(e)^{-t} \mathrm{~d} t, \\
\text { s.t. } \quad x^{*}(t)=x(t)+k x(t)-\gamma v(t), \\
x\left(t_{0}\right)=x_{0} .
\end{aligned}
$$

A set of value functions $V_{\tau}(x)$ and $V_{c}(x)$ are established, so that the state function has one and only solution $x(t)$, which can be obtained by establishing the Hamilton-JacobiBellman (HJB) equation.

$$
\begin{aligned}
& V_{\tau}(x)=\max \left\{\alpha \gamma \varphi(t)-\frac{C_{1}}{2}\left[\varphi(t)^{2}\right]-\theta x(t)+V_{\tau}^{\prime}(x)\{x(t)+k x(t)-\gamma \varphi(t)-\gamma \nu(t)\}\right\}, \\
& V_{c}(x)=\max \left\{\beta \gamma v(t)-\frac{C_{2}}{2}\left[v(t)^{2}\right]-\pi x(t)+V_{c}^{\prime}(x)\{x(t)+k x(t)-\gamma \varphi(t)-\gamma v(t)\}\right\} .
\end{aligned}
$$


TABle 1: Parameters of differential game models of the central government, the local government, and coal mine enterprises.

\begin{tabular}{|c|c|}
\hline Symbol of parameter & Description of parameter \\
\hline$T$ & Time \\
\hline$K$ & Diffusion coefficient \\
\hline$\Gamma$ & Amount of reduced loss per unit effort \\
\hline$C_{1}$ & Cost coefficient of the local government for coal mine emergencies \\
\hline$C_{2}$ & Emergency cost coefficient for coal mine enterprises in sudden disasters \\
\hline A & Benefit brought to the local government per unit reduced accident loss \\
\hline B & Benefits brought to coal mine enterprises per unit reduced accident loss \\
\hline $\mathrm{H}$ & Degree of rewards and punishments by the central government for the local ones \\
\hline M & Degree of reward and punishments by the local government for the mine enterprises \\
\hline$\varepsilon_{c}$ & Degree of emergency supervision by the local government \\
\hline$\varepsilon_{l}$ & Degree of emergency supervision by the central government \\
\hline$g_{c}$ & Emergency performance level coefficient of the central government \\
\hline$g_{l}$ & Emergency performance level coefficient of the local government \\
\hline$\Theta$ & Coefficient of unit loss caused by sudden coal mine accident to the local government \\
\hline$\Pi$ & Coefficient of unit loss caused by sudden coal mine accident to the coal mine enterprises \\
\hline
\end{tabular}

The solution of $\varphi(t)$ in formula (6) is maximized under the first-order condition:

$$
\begin{aligned}
\alpha \gamma-C_{1} \varphi(t)-\gamma V_{\tau}^{\prime}(x) & =0, \\
\varphi^{*}(t) & =\frac{\alpha \gamma-V_{\tau}^{\prime}(x)}{C_{1}} .
\end{aligned}
$$

The solution of $v(t)$ in formula (7) is maximized under the first-order condition:

$$
\beta \gamma-C_{2} v(t)-\gamma V_{c}^{\prime}(x)=0
$$$$
v^{*}(t)=\frac{\beta \gamma-\beta V_{c}^{\prime}(x)}{C_{2}} .
$$

$V_{\tau}(x)=\tau_{1}+m_{1} x(t)$ and $V_{C}(x)=\tau_{2}+m_{2} x(t)$ where $\tau_{1}, \tau_{2}, m_{1}$, and $m_{2}$ are all constants. Formulae $V_{\tau}^{\prime}(x)=m_{1}$ and $V_{\tau}^{\prime}(x)=m_{2}$ are substituted in formulae (6) and (7):

$$
\begin{aligned}
& \tau_{2}+m_{1} x(t)=\max _{\varphi(t)>0}\left\{\alpha \gamma v(t)-\frac{C_{1}}{2}\left[\varphi(t)^{2}\right]-\theta x(t)+m_{1}[x(t)+k x(t)-\gamma \varphi(t)-\gamma v(t)]\right\}, \\
& \tau_{2}+m_{2} x(t)=\max _{v(t)>0}\left\{\beta \gamma v(t)-\frac{C_{2}}{2}\left[v(t)^{2}\right]-\pi x(t)+m_{2}[x(t)+k x(t)-\gamma \varphi(t)-\gamma v(t)]\right\} .
\end{aligned}
$$

Then,

$$
\begin{aligned}
& m_{1}=\frac{\theta}{k}, \\
& m_{2}=\frac{\pi}{k} .
\end{aligned}
$$

The above coefficients are substituted in formulae (9) and (11):

$$
\begin{gathered}
\varphi^{*}(t)=\frac{\alpha k-\theta}{k C_{1}} \gamma \quad \alpha k \geq \theta, \\
v^{*}(t)=\frac{\beta k-\pi}{k C_{2}} \gamma \quad \beta k \geq \pi .
\end{gathered}
$$

The above solutions disclose the following conclusions. The efforts of the local government and coal mine enterprises in emergency response are negatively correlated with their respective emergency response cost, and the decreasing gradient are $\alpha k-\theta / k C_{1}^{2}$ and $\beta k-\pi / k C_{2}^{2}$, respectively.

Demonstration: the first-order partial derivative of $\varphi^{*}(t)$ with $C_{1}$ is obtained and $\partial \varphi^{*}(t) / \partial C_{1}=-(\alpha k-\theta) \gamma / k C_{1}^{2}<0$, which indicates that $\varphi^{*}(t)$ is monotonically decreasing with $C_{1}$. That is, when the local government lowers the emergency cost, the efforts and enthusiasm for emergency response will both be improved.

The first-order partial derivative of $v^{*}(t)$ with $C_{2}$ is obtained and $\partial v^{*}(t) / \partial C_{2}=(\beta k-\pi) \gamma / k C_{2}^{2}<0$, which means that $v^{*}(t)$ is monotonically decreasing with $C_{2}$. That is, when the cost of coal mine enterprises for emergency response decreases, the efforts and enthusiasm for emergency response will increase.

4.2. Situation 2: Rewards and Punishments Mechanism Is Introduced. The objective function of the expected benefits of the local governments is 


$$
\int_{0}^{t}\left\{\operatorname{a\gamma } \varphi(t)-\frac{C_{1}}{2}[\varphi(t)]^{2}-\theta x(t)+\frac{\eta \varepsilon_{\tau}}{2}\left[g_{\tau} \varphi(t)-g_{\tau 0} \varphi_{0}(t)\right]-\frac{\mu \varepsilon_{c}}{2}\left[g_{c} v(t)-g_{c 0} v_{0}(t)\right]\right\} e^{-1} \mathrm{~d} t .
$$

The objective function of the expected benefits of coal mine enterprises is

$$
\int_{0}^{t}\left\{\beta \gamma v(t)-\frac{C_{2}}{2}[v(t)]^{2}-\pi x(t)+\frac{\mu \varepsilon_{c}}{2}\left[g_{c} v(t)\right]-g_{c 0} v_{0}(t) e^{-1} \mathrm{~d} t\right.
$$

The problem is transformed into

$$
\begin{aligned}
\max J_{\tau} & =\max _{\varphi(t)} \int_{0}^{t}\left\{a \gamma \varphi(t)-\frac{C_{1}}{2}[\varphi(t)]^{2}-\theta x(t)+\frac{\eta \varepsilon_{\tau}}{2}\left[g_{\tau} \varphi(t)-g_{0} \varphi_{0}(t)\right]-\frac{\mu \varepsilon_{c}}{2}\left[g_{c} v(t)-g_{c 0} v_{0}(t)\right]\right\} e^{-1} \mathrm{~d} t, \\
\max _{c} & =\max _{v(t)} \int_{0}^{t}\left\{\beta \gamma v(t)-\frac{C_{2}}{2}[v(t)]^{2}-\pi x(t)+\frac{\mu \varepsilon_{c}}{2}\left[g_{c} v(t)\right]-g_{c 0} v_{0}(t) e^{-1} \mathrm{~d} t,\right. \\
\text { s.t. } \quad x^{*}(t) & =x(t)+k x(t)-\gamma u(t)-\gamma v(t), x\left(t_{0}\right)=x_{0} .
\end{aligned}
$$

Solutions are obtained through the HJB method:

$$
\begin{array}{cc}
\varphi^{*}(t)=\frac{\alpha \gamma+\eta \varepsilon_{\tau} g_{\tau} / 2-\theta / k \gamma}{C_{1}}, \quad\left(2 \alpha \gamma+\eta \varepsilon_{\tau} g_{\tau} \geq \frac{2 \theta \gamma}{k}\right), \\
v^{*}(t)=\frac{\beta \gamma+\mu \varepsilon_{c} g_{c} / 2-\pi / k \gamma}{C_{2}}, \quad\left(2 \beta \gamma+\mu \varepsilon_{c} g_{c} \geq \frac{2 \pi \gamma}{k}\right) .
\end{array}
$$

4.3. Results and Discussion. According to the above resolutions, the following conclusions can be obtained:

(1) The efforts of emergency response by the local government and coal mine enterprises are negatively correlated with their respective emergency cost, and the decreasing gradients are $\left(\left(2 \alpha \gamma k+\eta \varepsilon_{\tau} g_{\tau} k-\theta \gamma\right)\right.$ $/ k C_{1}^{2}$ and $\left(2 \beta \gamma k+\eta \varepsilon_{c} g_{c} k-\pi \gamma\right) / k C_{2}^{2}$, respectively.

Demonstration: the first-order partial derivative of $\varphi^{*}(t)$ with $C_{1}$ is obtained and $\partial \varphi^{*}(t) / \partial C_{1}$ $=-\left(2 \alpha \gamma k+\eta \varepsilon_{\tau} g_{\tau} k-\theta \gamma\right) / k C_{1}^{2}<0$, which suggests that $\varphi^{*}(t)$ is monotonically decreasing with $C_{1}$. That is, when the local government reduces its emergency response cost, the efforts and enthusiasm for emergency response will both rise.

The first-order partial derivative of $v^{*}(t)$ with $C_{2}$ is obtained and $\partial v^{*}(t) / \partial C_{2}=-\left(2 \beta \gamma k+\mu \eta_{c} \varepsilon_{c} k-\pi \gamma\right)$ $\mid k C_{2}^{2}<0$, which means that $v^{*}(t)$ is monotonically decreasing with $C_{2}$. That is, when the coal mine enterprises reduce the emergency response cost, the efforts and enthusiasm for emergency response will both increase.
(2) The emergency efforts of the local governments $\varphi^{*}(t)$ are positively correlated with the degree of rewards and punishments $\eta$ by the central government; the increasing gradient is $\varepsilon_{\tau} g_{\tau} / 2 C_{1}$.

Demonstration: the first-order partial derivative of $\varphi^{*}(t)$ with $\eta$ is obtained and $\varphi^{*}(t) / \partial \eta=\eta \varepsilon_{\tau} g_{\tau} / 2 C_{1}$. The values of $\varepsilon_{\tau}, g_{\tau}$, and $C_{1}$ are all positive; then $\varepsilon_{\tau} g_{\tau} / 2 C_{1}>0$; that is, $\partial \varphi^{*}(t) / \partial \eta$ is always positive, which means that $\varphi^{*}(t)$ is monotonically increasing with $\eta$. With the increase in rewards or punishments of the central government, the efforts of the local government will increase in the CME response. As a result, the enthusiasm of the local government to participate in emergency work will be improved notably.

(3) The emergency efforts of the local government $\varphi^{*}(t)$ are positively correlated with the central government's supervision $\varepsilon_{\tau}$; the increasing gradient is $\eta g_{\tau} / 2 C_{1}$.

Demonstration: the first-order partial derivative of $\varphi^{*}(t)$ with $\varepsilon_{\tau}$ is obtained and $\partial \varphi^{*}(t) / \partial \varepsilon_{\tau}=\eta \varepsilon_{\tau} / 2 C_{1}$. The values of $\eta, g_{\tau}$, and $C_{1}$ are all positive; then $\eta g_{\tau} / 2 C_{1}>0$, which means that $\partial \varphi^{*}(\mathrm{t}) / \partial \varepsilon_{\tau}$ is always positive and $\varphi^{*}(t)$ is monotonically increasing with $\varepsilon$ l. With the enhancement of supervision by the central government, the efforts of local government increase in the CME response, thus increasing the enthusiasm of the local government to participate in the work.

(4) The emergency efforts of the local government $\varphi^{*}(t)$ are positively correlated with the performance evaluation by the central government $\mathrm{g} l$; the increasing gradient is $\eta g_{\tau} / 2 C_{1}$. 
Demonstration: the first-order partial derivative of $\varphi^{*}(t)$ with $g l$ is obtained, and $\partial \varphi^{*}(t) / \partial g_{\tau}=\eta g_{\tau} / 2 C_{1}$. The values of $\eta, \varepsilon_{\tau}$, and $C_{1}$ are all positive; then $\eta g_{\tau} / 2 C_{1}>0$; that is, the value of $\partial \varphi^{*}(\mathrm{t}) / \partial g_{\tau}$ is always positive, which indicates that $\varphi^{*}(t)$ is monotonically increasing with $g_{\tau}$. In other words, with the improvement of the performance evaluation of the local government by the central government, the emergency efforts of the local government increase. Resultantly, the local government participates in emergency management work more actively.

(5) The emergency efforts of coal mine enterprises $V^{*}(t)$ are positively correlated with the emergency rewards and punishments by the local government to coal mine enterprises $\mu$, with an increasing gradient of $\varepsilon_{c} g_{c} / 2 C_{2}$.

Demonstration: the first-order partial derivative of $v^{*}(t)$ with $\mu$ is obtained; then $\partial v^{*}(t) / \partial \mu=\varepsilon_{c} g_{c} / 2 C_{2}$. The values of $\varepsilon_{c}, g_{c}$, and $C_{2}$ are all positive; then $\varepsilon_{c} g_{c} / 2 C_{2}>0 . V^{*}(t)$ is monotonically increasing with $\mu$. That is, with the increase in the rewards and punishments from the local government, the efforts for emergency work of coal mine enterprises increase. Then, the enthusiasm of the coal mine enterprises to participate in emergency work will jump.

(6) The emergency efforts of coal mine enterprises $V^{*}(t)$ are positively correlated with the emergency supervision by the local government $\varepsilon_{c}$ over coal mine enterprises, and its increasing gradient is $\mu g_{c} / 2 C_{2}$.

Demonstration: the first-order partial derivative of $V^{*}(t)$ with $\varepsilon_{c}$ is obtained; $\partial v^{*}(t) / \partial \varepsilon_{c}=\mu g_{c} / 2 C_{2}$. The values of $\mu, g_{c}$, and $C_{2}$ are all positive; then $\mu g_{c} / 2 C_{2}>0$. This suggests that $V^{*}(t)$ is monotonically increasing with $\mu$. As the supervision by the local government intensifies, coal mine enterprises will pay more efforts in emergency work, and the enthusiasm of enterprises to participate in emergency work increases.

(7) The emergency efforts of coal mine enterprises $V^{*}(t)$ are positively correlated to the emergency performance evaluation level of the local government to coal mine enterprises $g_{c}$, with an increasing gradient of $\mu \varepsilon_{c} / 2 C_{2}$.

Demonstration: the first-order partial derivative of $V^{*}(t)$ with $g_{c}$ is obtained; $\partial v^{*}(t) / \partial g_{c}=\mu \varepsilon_{c} / 2 C_{2}$. The values of $\mu, \varepsilon_{c}$, and $C_{2}$ are all positive; then $\mu \varepsilon_{c} / 2 C_{2}>0$, which means that, with the improvement of the performance evaluation level from the local government to coal mine enterprises, the efforts in CME management of coal mine emergencies increase and the enthusiasm of coal mine enterprises to participate in emergency work will be greatly promoted.

The following conclusions can be drawn through a contrastive analysis on the CME management efforts of the local government and coal mine enterprises in Situations 1 and 2. Both local government and coal mine enterprises pay fewer emergency efforts in Situation 1 than in Situation 2. That is, coal mine enterprises and the local government improve their emergency efforts to some extent for the introduction of incentive mechanism and supervision and evaluation mechanism. This will improve the efficiency and level of emergency response.

\section{Numerical Simulation}

In the hope of intuitively expressing evolutions of game behavior among the central government, the local governments, and coal mine enterprises in CME management synergy, numerical simulation analysis is conducted with the aid of MATLAB software based on the above stability analysis on the evolutionary stabilization strategy of the synergy evolutionary game system for CME response. Since it is difficult to get emergency-related data when a coal mine accident occurs, the relevant parameters are assigned according to the constraints of the research results, such as $\alpha \mathrm{k} \geq$ ?, $\beta \mathrm{k} \geq \pi, 2 \alpha \gamma+\eta \tau \mathrm{g} \tau \geq \theta \gamma / k$, and $2 \beta \gamma+\mu \mathrm{cgc} \geq \pi \gamma / k$, and the parameter assignment only represents the relative relationship among the parameters. Given that the benefits to local governments from each reduction of coal mine accident losses include social benefits from the whole area, it is assumed that $\alpha>\beta$. The unit loss caused by a coal mine accident to the local government is the loss from the whole area, so $\pi>\theta$. The specific parameter assignment is shown in Table 2.

The relationships between emergency response efforts and emergency response costs of the local government in the two cases, i.e., the introduction and absence of supervision, assessment, and incentive mechanism, are obtained by numerical simulation using MATLAB software (Figure 3). In both cases, the emergency effort of the local government decreases with the increase of emergency cost. Meanwhile, according to the curve trend, the emergency effort decreases the most sharply in the initial stage, and it tends to level off eventually. Moreover, the relationships between the emergency effort and the emergency cost almost overlap in these two cases, indicating that supervision, assessment, and incentive mechanism do not lead to significant fluctuations of the relationship between the emergency effort and the emergency cost. This suggests that the loss of self-interest due to emergency inputs is the main concern of the local government in the emergency synergy process.

Similarly, the relationships between emergency response efforts and emergency response costs of mine enterprises in the two cases, i.e., the introduction and absence of supervision, assessment, and incentive mechanism, are obtained by numerical simulation using MATLAB software (Figure 4).

As shown in Figure 4, in both cases, the emergency response effort of coal mine enterprises decreases as the emergency response cost increases. In addition, the emergency response effort of coal mine enterprises is higher in the case of introduction of supervision, assessment, and incentive mechanism than in the case of obscene of these measures. According to the curve trend, in both cases, the emergency response efforts of coal mine enterprises and the local government will drop sharply with the increase of emergency response cost and eventually level off, which 
TABLE 2: Parameter assignment.

\begin{tabular}{lccc}
\hline Symbols for quantities & Assignment & Symbols for quantities & \\
\hline$g_{l}$ & 0.5 & $\eta$ & $\mu$ \\
$\mathrm{K}$ & 0.8 & $\mu$ & 0.5 \\
$\gamma$ & 6 & $\varepsilon_{l}$ & 0.5 \\
$\mathrm{C}_{1}$ & 7 & $\varepsilon_{\mathrm{c}}$ & 0.5 \\
$\mathrm{C}_{2}$ & 8 & $\mathrm{gc}$ & 0.5 \\
$\mathrm{~A}$ & 15 & $\pi$ & 0.5 \\
$\beta$ & 10 & $\theta$ & 5 \\
\hline
\end{tabular}

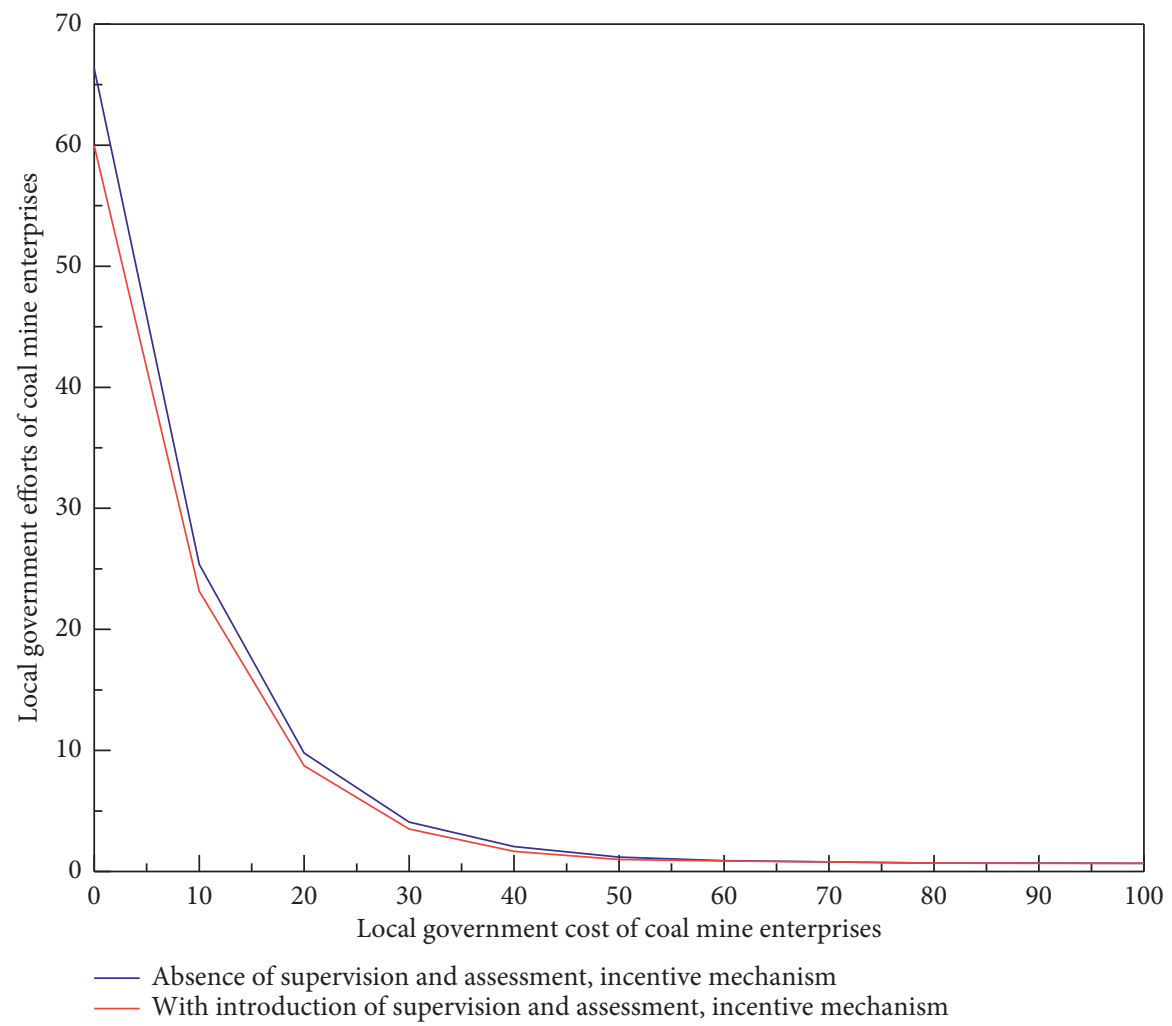

FiguRE 3: Relationships between emergency response efforts and emergency response costs of the local government in two cases.

indicates that whether coal mine enterprises positively participate in emergency rescue is mainly determined by the cost of emergency inputs.

The simulation curve of the relationship between the emergency response effort of the local government and the diffusion trend of a sudden coal mine disaster is plotted according to the value of $k$ (Figure 5). When the diffusion coefficient $k>0$, that is, when damages or casualties have been caused by deterioration of the coal mine disaster, the emergency effort of the local government increases as the coal mine disaster deteriorates in both cases. According to the curves, the relationship between the emergency response effort of the local government and the diffusion trend of a sudden coal mine disaster almost coincides in both cases. This demonstrates that when a coal mine disaster deteriorates, the emergency response effort of the local government is not notably affected by the introduction of supervision, assessment, and incentive mechanism; instead, it is primarily influenced by the diffusion of the deteriorating coal mine disaster. 


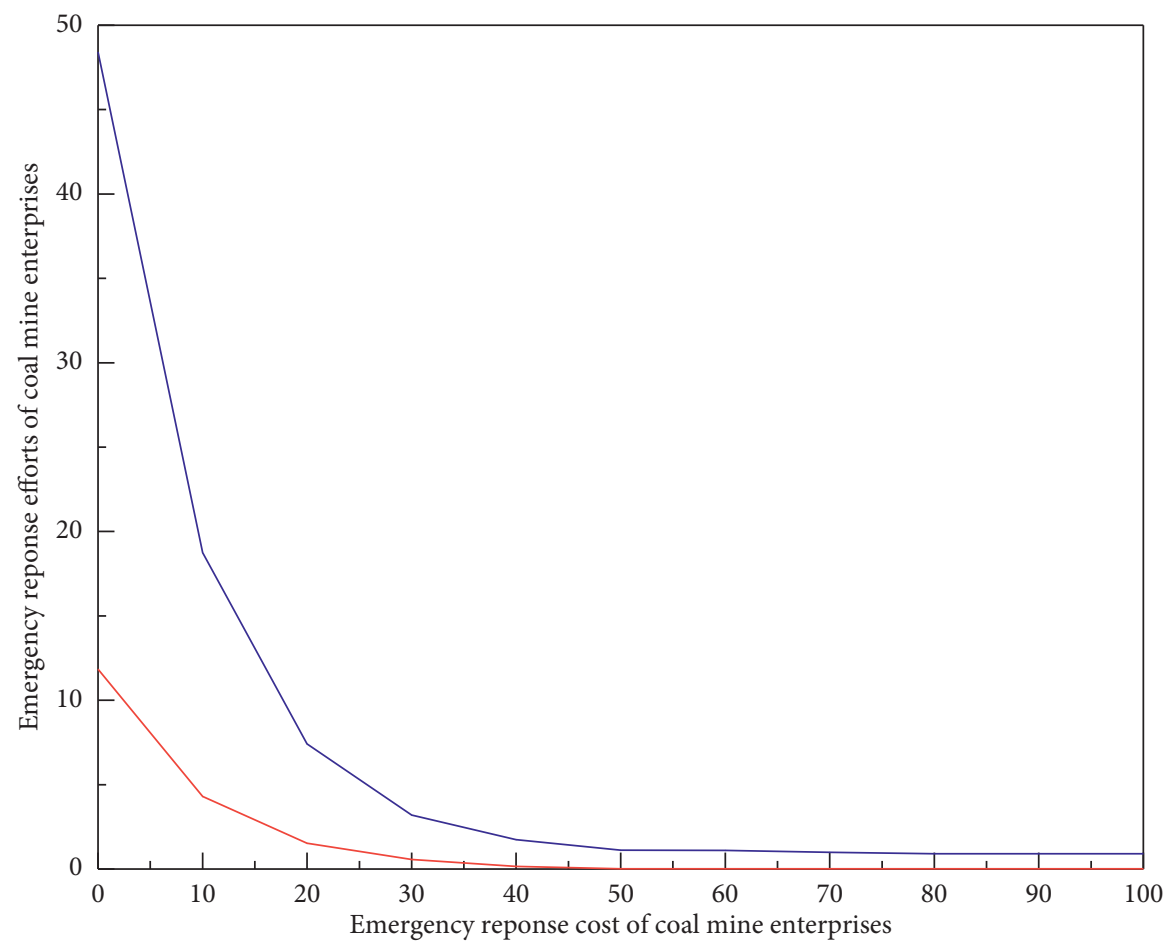

- Absence of supervision and assessment, incentive mechanism

- With introduction of supervision and assessment, incentive mechanism

FIGURE 4: Relationships between emergency response efforts and emergency response costs of coal mine enterprises in two cases.

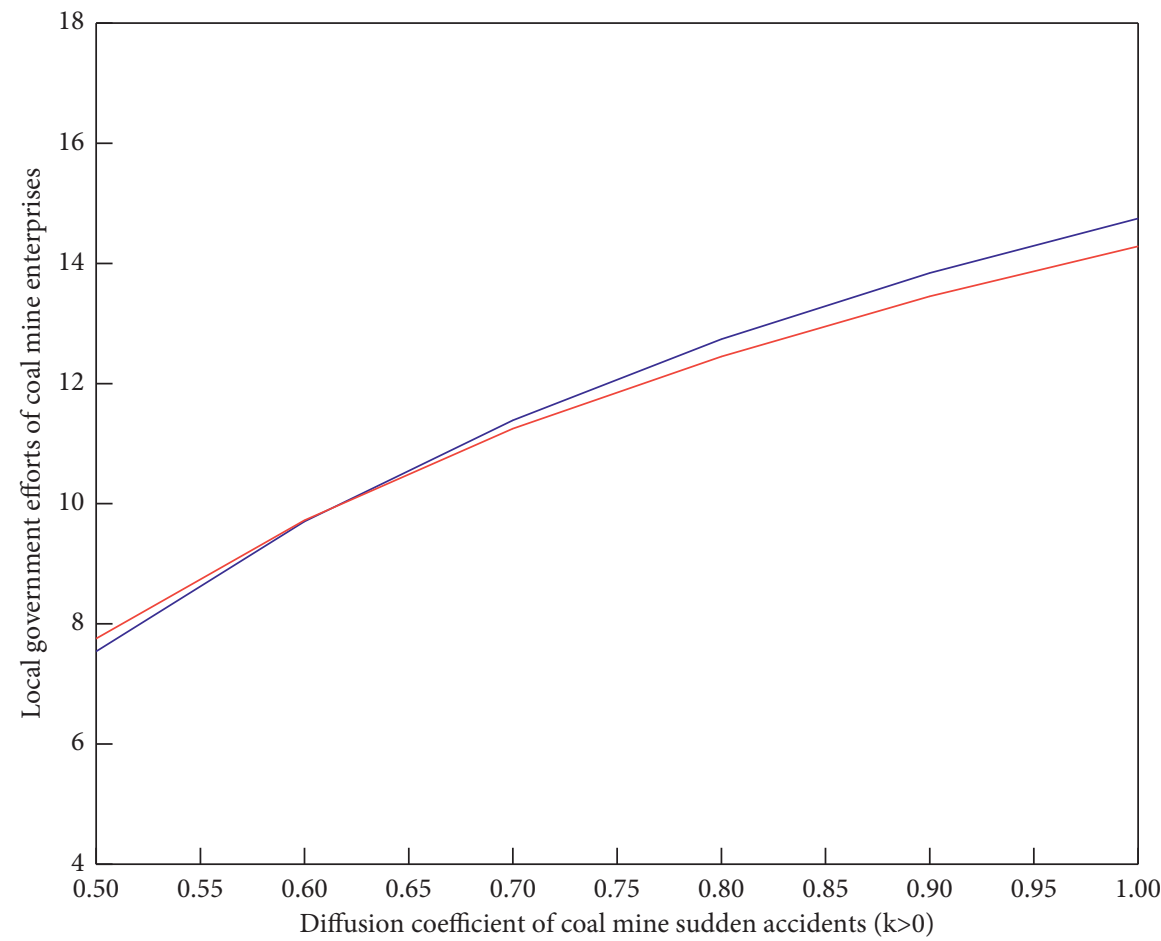

Absence of supervision and assessment, incentive mechanism

With introduction of supervision and assessment, incentive mechanism

FIGURE 5: Relationship between the emergency effort of the local government and the diffusion trend of a sudden coal mine disaster $(\mathrm{k}>0)$. 


\section{Conclusions}

This study analyzed the interest relationship and conflicts among the subjects involved in the regional CME management synergy system and established differential game models among the central government, the local government, and coal mine enterprises in emergency response based on the differential game theory. Furthermore, a contrastive analysis was made on the synergy of the three subjects before and after the introduction of supervision, evaluation, rewards, and punishments. The following findings were obtained: no matter the mechanisms are introduced or not, the respective emergency efforts are negatively correlated with the respective emergency costs for both local government and coal mine enterprises; the emergency efforts of the local government are positively correlated with the degree of supervision and evaluation as well as rewards and punishment by the central government; and the efforts of coal mine enterprises are positively correlated with the degree of supervision and evaluation as well as rewards and punishments by the local government. In addition, a contrastive study on the emergency efforts and synergy benefits of the three subjects under two situations reveals that the emergency cost is crucial for the emergency efforts of each subject. The introduction of the rewards and punishments can improve the emergency efforts and the emergency synergy profits in CME. Compared with the supervision and evaluation degree, the emergency cost exerts a more direct and significant impact on the emergency enthusiasm of coal mine enterprises and the local government. The research results suggest that the supervision and evaluation and the rewards and punishments can improve the emergency efforts of all subjects in the regional CME management system and promote the realization of the synergistic effect in regional CME, but the emergency cost is the key to the emergency efforts of coal mine enterprises.

According to the research conclusions, it is suggested that when formulating emergency synergy policies in the future, the local and central governments should focus on how to establish a compensation mechanism and incentive mechanism for SME response costs. Only in this way can the enthusiasm and efforts of each subject be promoted and the efficiency of emergency synergy be improved.

\section{Data Availability}

The data used to support the findings of this study are available from the first author or corresponding author upon request.

\section{Conflicts of Interest}

The authors declare that they have no conflicts of interest with respect to the research, authorship, and/or publication of this article.

\section{Acknowledgments}

This paper was partially supported by Postdoctoral Research Foundation of Henan Province (Grant no. 2019728) and Young Key Teachers in Henan Polytechnic University (2018XQG-21).

\section{References}

[1] N. Kapucu and V. Garayev, "Collaborative decision-making in emergency and disaster management," International Journal of Public Administration, vol. 34, no. 6, pp. 366-375, 2011.

[2] M. Ishiwatari, "Institutional Coordination of disaster management: engaging national and local governments in Japan," Natural Hazards Review, vol. 22, no. 1, Article ID 04020059, 2021.

[3] M. Greenberg, "Book r," Risk Analysis, vol. 24, no. 4, pp. 1068-1069, 2004.

[4] L. Palen, S. R. Hiltz, and S. B. Liu, "Online forums supporting grassroots participation in emergency preparedness and response," Communications of the ACM, vol. 50, no. 3, pp. 54-58, 2007.

[5] L. K. Comfort, "Integrating organizational action in emergency management; strategies for change," Public Administration Review, vol. 45, pp. 155-164, 1985.

[6] N. Kapucu and Q. Hu, "Understanding multiplexity of collaborative emergency management networks," The American Review of Public Administration, vol. 46, no. 4, pp. 399-417, 2016.

[7] R. McMaster and C. Baber, "Multi-agency operations: cooperation during flooding," Applied Ergonomics, vol. 43, no. 1, pp. 38-47, 2012.

[8] P. Salama, P. Spiegel, L. Talley, and R. Waldman, "Lessons learned from complex emergencies over past decade," The Lancet, vol. 364, no. 9447, pp. 1801-1813, 2004.

[9] S. Curnin, C. Owen, D. Paton, and B. Brooks, "A theoretical framework for negotiating the path of emergency management multi-agency coordination," Applied Ergonomics, vol. 47 , pp. $300-307,2015$.

[10] J. Z. Hernández and J. M. Serrano, "Knowledge-based models for emergency management systems," Expert Systems with Applications, vol. 20, no. 2, pp. 173-186, 2001.

[11] G. Te Brake, R. Van der Kleij, and M. Cornelissen, "Distributed mobile teams: effects of connectivity and map orientation on teamwork," in Proceedings of the 5th international ISCRAM conference, Washington, DC, USA, May 2008.

[12] D. Henstra, "Evaluating local government emergency management programs: what framework should public managers adopt?" Public Administration Review, vol. 70, no. 2, pp. 236-246, 2010.

[13] N. Kapucu and V. Garayev, "Designing, managing, and sustaining functionally collaborative emergency management networks," The American Review of Public Administration, vol. 43, no. 3, pp. 312-330, 2013.

[14] B. Chen, P. Zhou, D. Zhu, and J. L. Chen, "The complex alarming event detecting and disposal processing approach for coal mine safety using wireless sensor network," International Journal of Distributed Sensor Networks, vol. 8, no. 11, Article ID 280576, 2012.

[15] X. C. Li and Q. L. Liu, "Empirical study on the simulation model of emergency disposal process of coal mine accidents," China Population Resources \& Environment, vol. 24, no. 2, pp. 154-160, 2014.

[16] H. L. Qi and Y. C. Ning, "Assessment of coal mine safety and emergency management capability based on extenics theory," Coal Engineering, vol. 48, no. 9, pp. 161-164, 2016.

[17] E. Calixto and E. L. Larouvere, "The regional emergency plan requirement: application of the best practices to the Brazilian Case," Safety Science, vol. 48, no. 8, pp. 991-999, 2010. 
[18] B. Li, L. Huang, X. Lv, and Y. Ren, "Study on temperature variation and pore structure evolution within coal under the effect of liquid nitrogen mass transfer," ACS Omega, vol. 6, no. 30, pp. 19685-19694, 2021.

[19] B. Li, J. Zhang, Z. Ding, B. Wang, and P. Li, "A dynamic evolution model of coal permeability during enhanced coalbed methane recovery by $\mathrm{N} 2$ injection: experimental observations and numerical simulation," RSC Advances, vol. 11, no. 28, pp. 17249-17258, 2021.

[20] J. L. Wang and L. Y. Sheng, "Backtracking and prospect on emergency management research of coal mine enterprises in Chinar - biblio metric analysis based on Cite Space knowledge graph," Journal of Safety Science and Technology, vol. 14, no. 9, pp. 175-179, 2018.

[21] Z. He, Q. Wu, L. Wen, and G. Fu, "A process mining approach to improve emergency rescue processes of fatal gas explosion accidents in Chinese coal mines," Safety Science, vol. 111, pp. 154-166, 2019.

[22] J. G. Zhang and X. J. Xiang, "The research on problems and suggestions in the preparation of emergency plan for coal mine accidents in China," Coal Economic Research, vol. 40, no. 2, pp. 70-93, 2020.

[23] L. Wang, Y. Wang, Q. Cao, X. Li, J. Li, and X. Wu, "A framework for human error risk analysis of coal mine emergency evacuation in China," Journal of Loss Prevention in the Process Industries, vol. 30, pp. 113-123, 2014.

[24] S. T. Hu, "Study on the joint transformation of local coal mine by large state-owned coal enterprises," China Coal, vol. 34, no. 1, pp. 18-20, 2008.

[25] Y. Liu, Z. Fan, and H. Qi, "Dynamic statistical evaluation of safety emergency management in coal enterprises based on neural network algorithms," Journal of Intelligent and Fuzzy Systems, vol. 39, no. 4, pp. 5521-5534, 2020.

[26] H. Y. Yang, "Discussion on the merger of the mine rescue team and the fire station," Coal Engineering, vol. S1, pp. 106-108, 2012.

[27] H. L. Qi and Y. C. Ning, "Research on mine safety emergency management synergy mechanism and countermeasures ability," Coal Technology, vol. 33, no. 12, pp. 182-184, 2014.

[28] J. F. Wang, L. J. Feng, and X. Q. Zhai, "A system dynamics model of flooding emergency capability of coal mine," Przeglad Elektrotechniczny, vol. 88, no. 9B, pp. 209-211, 2012.

[29] H. Q. Wang, J. Zhao, and H. L. Qi, "Research based on collaborative regional coal mine emergency management system," Coal Economic Research, vol. 36, no. 12, pp. 66-69, 2016.

[30] J. F. Wang, H. Y. Chang, X. Q. Zhai, and L. J. Feng, “Analysis on evolution game and simulation of coal mine emergency cooperation," Mining Safety \& Environmental Protection, vol. 44, no. 4, pp. 110-114, 2017. 